\title{
PARTO NA CONTEMPORANEIDADE: PERSPECTIVAS ANTROPOLÓGICAS
}

Carmen Susan Tornquist ${ }^{1}$

\section{Resumo:}

Este artigo busca analisar uma das tensões que marca o campo do parto humanizado contemporâneo, que se estrutura em torno de dois sujeitos de direito (mulher e feto/bebê), comparando tal situação com aquelas relativas a outros contextos sociais. Através de dados coletados de diferentes pesquisas etnográficas, qualitativas, em diferentes regiões do país, busca relativizar noções contemporâneas relacionadas ao Parto Humanizado.

Palavras-Chave: Assistência ao parto; Antropologia; Relações de gênero.

As situações que envolvem o parto e o nascimento, evento ritualístico tão celebrado em nossa sociedade envolvem tensões bastante similares àquelas que estão presente no campo da discussão sobre o aborto e, também, das novas tecnologias da reprodução. Nestes processos - o revés do parto e adoção de técnicas altamente sofisticadas de cultivo e de controle da fecundidade tendo em vista uma concepção "natural" - encontramos as mesmas personagens: mulheres, fetos/embriões, crianças, pais e médicos, sejam através de presenças e ausências corpóreas e simbólicas.

Cabe destacar, também, para evitar quaisquer mal-entendidos acerca da perspectiva antropológica, que o processo do parto, ou seja, a concepção, a gravidez, o momento em que a mulher dá à luz e que o bebê "nasce", até o puerpério, são processos sempre reféns da cultura. Van Gennep destaca que as sociedades sempre procuram demarcar seus valores, ainda que de forma invertida - em situações que constituem os sujeitos sociais. Neste sentido, o parto é citado como um rito de passagem para a mulher e para o bebê que é iniciado no mundo externo, o que poderia ser visto como um ritual de iniciação e/ou de passagem a depender das cosmologias que envolvem o grupo no qual se inserem.

Tendo por foco as técnicas corporais, Marcel Mauss (1974), no início do século $X X$, além de argumentar que há inúmeras maneiras de uma mulher dar à luz, a depender da cultura, coloca que os fenômenos corporais são, a um só tempo, fisiológicos, psíquicos e culturais, descartando com isto a idéia de que seria possível um parto natural, situado fora da cultura. Algo que sugere, Michel Odent (1999), por exemplo,quando diz que as culturas "atrapalham o parto", quando, de um ponto de vista antropológico, a questão seria pensar onde e quando teria sido possível uma mulher dar à luz sem estar situada na sua humanidade mesma, que nos condiciona - enquanto seres da natureza

1 Doutora em Antropologia Social pela UFSC; Professora de Ciências Sociais do Centro de Ciências da Educação da Universidade do Estado de Santa Catarina - UDESC; participante da comissão editorial da Revista Estudos Feministas e pesquisadora associada do Núcleo de Identidades de Gênero e Subjetividades, do Laboratório de Antropologia da UFSC. E-mail: carmentornquist@ hotmail.com . 
propriamente humana, sermos sempre, e em todo lugar, reféns e mestres do mundo simbólico, da produção/reprodução de significados. Creio que é um ponto que causa grandes mal-entendidos entre a perspectiva antropológica strictu sensu e uma representação que a Antropologia tem em disciplinas e/ou meios sociais que simpatizam com seu relativismo e vínculo congênito com povos não-civilizados, em alguns aspectos mais simples do que nós, mas cuja complexidade simbólica nos irmana profundamente.

Malinowski, estudioso que inaugura a Antropologia Moderna, relativista e centrada na etnografia (observação participante), adverte aos estudiosos que mantenham sempre aceso o farol da sinceridade metodológica, forma metafórica com a qual ele sustenta que as ciências antropológicas, tal qual as ciências físicas e exatas, deve sempre explicitar as condições em que foi feito o estudos e/ou experimento. Para ele - um pensador do início do século XX, adepto incondicional de uma visão de ciência que hoje nós re-consideramos era necessário deixar muito claro como os dados tinham sido obtidos, quem os havia coletado, quem tinham sido os informantes privilegiados, as situações em que tinha se ido a campo.

Seguindo esta inspiração, mas também acrescentando as reflexões pós-modernas acerca da presença da subjetividade na produção científica, gostaria de apresentar os dados que estou considerando neste artigo para pensar o parto hoje, evitando qualquer tentativa de encerrar a reflexão, mas estimulando que todos nós nos coloquemos como participantes do que Geertz chama de principal tarefa da Antropologia, que é o refinamento do debate. São eles: 1) a pesquisa que fiz acerca do movimento pela Humanização do Parto no Brasil, movimento civil, "teia de movimentos", no sentido que Ihes confere Alvarez et al. (2000), do qual participam, majoritariamente, profissionais de saúde(sejam do campo biomédico, seja do campo das terapias alternativas), que orbita em torno da REHUNA (Rede pela Humanização do parto e do nascimento), que foi criada em 1991 logo após a decisão da OMS em rever as políticas sociais para a atenção ao parto, a partir da Conferência de Fortaleza de 1988.

A partir deste momento, a OMS passa a falar em maternidade segura, em tecnologias apropriadas para o parto e nascimento, em hospital Amigo da Criança e a questionar a transformação do parto cesáreo em rotina (tornandoo epidêmico). Para realizar esta pesquisa de maior fôlego, realizei três etnografias: uma, junto aos rituais do movimento (congressos, encontros, reuniões, eventos) desta Rede, que inclui a realização de entrevistas formais e análise da literatura nativa (livros, revistas, sites, vídeos);outra, uma etnografia de uma maternidade reconhecida como humanizadas; e, por último, observação, participação e coleta de narrativas de parto em dois cursos de capacitação de parteiras "tradicionais".

Este conjunto de dados compõe uma etnografia multissituada e foram comparados com dados de outras pesquisas, de menor escopo, que compõe o segundo conjunto de dados que considero aqui, e que se referem à pesquisa documental realizada na primeira maternidade pública de Florianópolis e às narrativas de partos feitas por antigas parteiras, na mesma região, cujo processo de medicalização do parto é bastante recente (algo pouco comum para capitais situadas no litoral sul do País). Além disto, estou considerando 
também dados de uma pesquisa em andamento, acerca do "parto sem dor', vanguarda obstétrica que se tornou conhecida nos anos 50 , de diferentes maneiras, tanto na Europa quanto na América Latina, e que é considerado por Tânia Salem (1983) como antecessor do parto natural dos anos 70 cujo desdobramento nos 90 é o parto humanizado.

O processo de medicalização do corpo feminino e da assistência ao parto é um processo situado na longa duração cujas temporalidades são variáveis, a depender dos processos de modernização de diferentes sociedades e de diferentes grupos sociais. A medicalização que, na maioria dos países, significou a transferência do ritual do parto para a clínica médica (a instituição hospital) significou bem mais do que uma mudança de "endereço', tendo envolvido a patologização do evento, a destituição de redes de solidariedade e de saberes femininos acerca do assunto, a transformação de um evento familiar em um assunto do bio-poder, no sentido foucaultiano, a tentativas de higienização das condutas familiares, a consolidação de um sistema que alguns autores consideram fabril no que tange à assistência ao parto, vale dizer, a divisão do trabalho e conseqüente rotinização" e alienação por parte dos diferentes profissionais com ela envolvido. É o que Robbie Davis-Floyd (1984) chama de modelo tecnocrático da atenção ao parto, que é, também, marcado pela dimensão ritual, mas um ritual médico, carregado de valores e signos próprios de uma sociedade medicalizada - e que é, também, em função de sua trajetória histórica, uma sociedade patriarcal, marcada pela dominação masculina.

A obstetrícia e a assistência ao parto têm uma história, história esta marcada por grandes controvérsias e polêmicas, que, de certa forma, se reproduzem hoje: quem deve atender as parturientes? Qual o melhor local para prestar esta assistência? Qual a formação mínima exigida e/ou conhecimentos necessários para atender de forma mais eficaz um parto? Pode alguém acompanhar o parto? Como funcionam os corpos das mulheres, como são suas dinâmicas, como lidar com os sofrimentos, dores e prazeres do parto, isso sem falar nos próprios procedimentos técnicos que, também, tem uma longa história. Brigitte Jordan (1993) propõe que, para analisar o parto em diferentes culturas, deve-se observar quatro destes aspectos: quem atende a mulheres, em que local o faz, quem acompanha o parto e quais os procedimentos técnicos utilizados.

Cabe destacar, neste momento, que esta história da assistência ao parto envolveu profundos conflitos e tensões, ligados sobretudo as diferentes personagens que se candidataram a prestar assistência: parteiras e curandeiras, médicos, estudantes de medicina, parteiras diplomadas, enfermeiras de formação, midwifes e sage-femmes, tensões estas que têm sido alvo de estudos, que nos mostram por quê a instituição hospitalar, corporações médicas e o discurso biomédico gozam de poder político e simbólico na contemporaneidade, mesmo naquelas regiões nas quais não se faz materialmente, presente. No entanto, ainda que este peso se faça sentir em chamadas "áreas pobres e distantes" do Terceiro Mundo, ou seja, nas áreas em que a modernidade chega de forma bastante precária, as parteiras populares (ou parteiras "tradicionais", para usar a expressão da OMS/Ministério da Saúde) nunca deixaram de atuar. 
Ainda que hoje possam ser vistas como "alternativas" que suprem uma falta - a falta dos serviços de saúde que não chegam ou que chegam em condições muito precárias - estas mulheres que atendem partos - pois nem sempre se autodenominam parteiras - têm tido um papel central não apenas no que se refere à atenção ao parto, mas também na manutenção, ainda que ressignificada" de saberes e conhecer sobre corpo, saúde e processos relacionados ao parto, de insuspeitada valia. Para os fins deste artigo, quero recuperar dois aspectos que me parecem bons para pensar nas tensões que estão colocadas no parto humanizado, e que, de um ponto de vista de uma antropologia feminista, podem nos desafiar mais ainda no que tange à crítica aos modelos de assistência ao parto que conhecemos, pelo menos no âmbito da modernidade hegemônica. São eles: a valorização de dois sujeitos/pessoa: a mulher, de um lado (a protagonista do parto) e a criança (protagonista do nascimento).

Sabemos que a historicamente a noção de indivíduo como Pessoa dotada de interioridade, razão e vontade (bases do individualismo moderno, à la Dumont) se restringiu aos homens, sendo os movimentos feministas, por exemplo, uma busca de sua ampliação as mulheres. Assim colocam Franccheto et.al. (1982), em um texto em que consideram o feminismo dentro do marco da ideologia individualista, em que apontam também para as dificuldades de "harmonizar" em uma mesma instância social (no caso, a família), tantos sujeitos /indivíduos: homens, mulheres e crianças. Antecipando de carta forma um dos grandes dilemas que penso hoje estarem colocados no que tange às relações entre as gerações, as autoras se perguntam até que ponto chegará esta disputa acirrada por direitos no domínio das famílias, que segundo as autoras, inspiradas em Dumont, seria uma instituição eminentemente hierárquica.

Em meu trabalho de campo, encontrei uma série de questões relacionadas a este dilema, e quero compartilhá-los com vocês. Selecionei algumas falas e situações relacionadas ao processo do parto que falam disto, como, por exemplo, Cibele, que escolheu dar à luz numa maternidade "humanizada", mas que, após uma série de complicações, atravessou um parto cesariano que, sem maiores explicações, foi-lhe impingindo pela médica, em função de uma série de riscos e em nome do bem-estar do bebê:

Eu estava cheia de dores e fissuras, não poderia suportar, os dias passavam, passava tudo que era coisa em mim para ver se vinha o leite, e nada. Eu já não tinha conseguido parir de cócoras, agora não conseguia amamentar, e sempre aquele enfermeira passando na porta, me chamando de mãezinha, e dizendo banco de leite, banco de leite!."(Cibele, 30 anos, música)

Segundo os relatos de profissionais de saúde, as queixas de Cibele não são isoladas, e já contam com críticos internos. Regina, auxiliar de enfermagem que atua no setor, relatou-me certa noite situações similares que assistiu, questionando: "Eu fico me perguntando, afinal, o que é humanização? Obrigar uma pessoa a fazer o que ela não está podendo?" Antônio, com sua longa experiência e sensibilidade particular, diz o seguinte: 
Saímos do extremo de não dar atenção, para um outro extremo que parece assim, quem não amamenta está sendo uma mãe errada, e se tu não der de mamar... tem uma mulher que chorava e ela dizia o seguinte: 'porque a fulana disse que se eu não der de mamar teu filho vai pra UTI!!"(...) Se não mamar ele vai ter hipoglicemia (Antônio, 48 anos, médico).

Carolina, jovem mãe de primeira viagem, como dizem na maternidade, colocou a boca no trombone durante um par de horas de seu trabalho de parto. Não atendendo aos olhares incomodados de enfermeiras e doutorandos, foi preciso que a obstetra lhe advertisse que o problema não era dela, mas de Leonardo(o bebê), que, se ela continuasse com aquele comportamento, sofreria conseqüências bastante graves, argumento ao qual, finalmente, Carol teve que se render. Qual a mulher que assumiria o ônus de prejudicar seu filho? Maria, acompanhada de um pai "grávido", fez de tudo para dar à luz de cócoras. Não conseguiu, e acabou sendo alvo de uma cesárea que não deixe de acarretar alguns problemas na seqüência do processo. No entanto, ao contrário de Cibele, foram relativamente contornados, e dois dias depois, encontrei o jovem casal "amamentando" a filha recém-nascida. Alegrias à parte, o pai confessou-me o quanto estava triste pelo fato de sua mulher não ter conseguido dar à luz da forma mais correta. No ideário do parto humanizado, construiu-se um modelo para parir, e um determinado modelo de mulher - que, se de um lado atribui positividade ao corpo feminino e este poder de dar à luz (de controlar a fertilidade), apresenta seu lado perverso quando algumas mulheres não atingem este ideal do belo parto. Não estariamos, aí, diante, de uma reiteração do velho bordão que idealiza " $A$ " maternidade (uma só forma de " maternidade")?

As inúmeras imagens que compõe a iconografia do ideário do parto humanizado são belas - há uma estetização do processo gravidez-partopuerpério, que faz sentido num contexto de camadas médias urbanas, para quem determinadas formas se constrói o corpo e se compartilha com padrões de beleza e sexualidade. No entanto, fica a pergunta: serão estas universalizáveis? E mais, não terão efeitos perversos também sobre aquelas que - mesmo investidas do imaginário do empoderamento - por motivos dos mais diversos, não conseguem alcançá-los? O caso de Maria traz à tona a figura do pai grávido - de certa forma, possuidor daquele corpo de sua mulher, assim como Renato, médico que deixa bem claro seu poder enquanto médico face a esta liberdade de escolha:

O fato de eu considerar o parto vertical melhor para você e para o neném, eu não vou cair no mesmo erro e te obrigar a ficar de cócoras... O meu papel é orientar. Agora você tem que decidir dentro de opções seguras para você e para o teu neném. Evidentemente, se você chegar aqui e quiser parar pendurada na janela, eu não posso permitir né? Agora, se tua opção for dentro de padrões internacionalmente aceitos, é outra história. O sentido é esse. O papel do médico é informar as opções. (Renato, médico, Florianópolis)

Apontando para os limites do direito das mulheres sobre o próprio corpo, Renato aponta para os deveres do médico, no contexto do bio-poder, em última instância, responsável pelas duas vidas. Vemos aqui que o ideário 
há tensões de difícil resolução, ligadas à existência de dois sujeitos de direito envolvidos no processo (criança e bebê). Ivan França e José R.Ayres chamam atenção para este dilema, tendo em vista a amamentação, segunda tarefa altamente idealizada que sobrecarrega as mulheres:

\begin{abstract}
"A prática da amamentação envolve pelo menos dois sujeitos de direito - mães e crianças. Não há dúvida quanto ao caráter intersubjetivo desta interação. Estes dois sujeitos, por sua vez, estão em interação com outros sujeitos, tais como homens-pais, familiares, profissionais de saúde ou educação, empresas e governos, tornando a prática da amamentação em ato, simultaneamente, individual e coletivo. (FRANÇA e AYRES, 2000).
\end{abstract}

Não se pode perder de vista a crescente valorização da criança, como um sujeito pleno de direitos na sociedade contemporânea; é fato que, com freqüência, leva ao obscurecimento da mãe enquanto sujeito, e sua redução à função de mediadora e única responsável pelo bom sucesso da amamentação e, no limite, à saúde biopsíquica da criança. Talvez, por isso, muitas vezes eu tenha escutado de profissionais perspicazes, em diferentes contextos, a ironia criada a partir do título Hospital Amigo da Criança: "Amigo da Criança e Inimigo da Mamãe".

Uma das grandes riquezas da Antropologia é a possibilidade de compararmos dados de um universo particular - ainda que dentro de uma mesma sociedade- com dados coletados em contextos distintos. No caso desta reflexão, pude comparar os dados observados - estes, que apontam para a tensão entre "mulher e feto/bebê" no campo da humanização do parto - com lógicas situadas em outros contextos simbólicos atuais e, também, em outros momentos históricos. Assim, quero caracterizar rapidamente algumas observações que têm sido feitas junto a mulheres de classes populares de origem rural, na qual se encontram práticas domiciliares de atenção ao parto, muitas vezes, feitas por parteiras ou outras mulheres que atendem partos e que são muito boas para que exercitemos nossa capacidade de relativização, compreendendo a presença de lógicas distintas daqueles que norteiam nossa forma de ver o parto. Como, por exemplo, as narrativas que coletei de parteiras no Vale do Jequitinhonha, e que revelam que seu prestígio advém de sua capacidade de atender bem os partos. Atender bem os partos envolve uma série de atributos, tais como: prontidão em atender a mulher que está precisando, generosidade e cuidado com esta mulher e seus familiares, capacidade de decisão e reconhecimento de sua autoridade por parte dos homens e familiares; experiência anterior com partos e, sobretudo, garantir a vida da parturiente.

Situadas em geral em regiões hoje bastante empobrecidas, por conta de processos históricos de desigualdade, as parteiras, em suas narrativas heróicas, enaltecem as dificuldades que enfrentam em seu mister e não escondem que perderam muitos meninos. No entanto, se estas perdas são lamentadas, são também vistas como "vicissitudes" da vida que, em última instância, não lhes pertencem, mas sim a Deus.Já as mortes maternas que, por desventura, tenham ocorrido em suas mãos, são vistas como pontos negativos em sua experiência, verdadeiras fontes de diminuição de seu prestígio. Uma parteira experiente, uma boa parteira, enfim, uma verdadeira parteira é aquela que salva vidas das mães. Diz dona Conceição: " Graças a 
Deus, eu nunca perdi nenhuma mulher!" Observei a mesma situação nos relatos que coletei na IIha de SC, referentes aos anos 60 e 70 . Outro aspecto que corrobora esta intensa valorização da mulher no processo do parto é a própria estrutura das narrativas de parto, nas quais o clímax da história não se dá quando o bebê nasce, mas sim quando a placenta ("mãe da vida" ou "parto") "nasce" ou é expulso do corpo da mulher.

Este aspecto contrasta fortemente com as narrativas de parto urbanas e modernas, não apenas as que escutamos e acompanhamos no campo do movimento, mas que circulam nas mídias, onde o clímax do parto é o nascimento do bebê, desaparecendo a figura da parturiente tão logo o mesmo aconteça. O que estes dados sugerem é que a vida e a saúde das mulheres tem uma maior valorização do que a vida dos bebês. Escutei vários relatos de situações em que as famílias verdadeiramente se rearranjavam quando da morte da mãe, figura central na manutenção da unidade doméstica em contextos rurais e populares. Estes relatos contrastam fortemente com a visão que atribui extremo valor ao bebê inclusive, antecipando a noção de pessoa aos primeiros momentos da gravidez, ou seja, logo após a concepção.

Vários estudos têm apontado para a consolidação deste processo, que atravessa o próprio discurso da genética, mas que encontramos em campo entre nossos informantes. $O$ feto já é um bebê- portanto, uma pessoa, ponto que explica porque, entre os adeptos do parto humanizado, a questão do aborto divide fortemente as opiniões e correntes internas do movimento.O que para nós, adeptos da humanização do parto, nos causa a principio, estranheza, talvez seja bom para pensar não em "desvalorização" da infância, mas em refletir sobre a secundarização - e quiçá, subalternização, uma vez mais - das mulheres no contexto da assistência ao parto e das relações sociais como um todo. Neste sentido, gostaria de pensar se não seria, antes, o caso de intentarmos mulherizar o parto, ao invés de nos contentarmos com a humanização da assistência.

\section{Referências}

ALVAREZ:DAGNINO; ESCOBAR. Cultura e política nos movimentos sociais latinoamericanos. Belo Horizonte: UFMG : 2000.

BOURDIEU, Pierre. La domination masculine. Paris : Editions du Seuil, 2002.

DAVIS-FLOYD,R. Birth as an american rite of passage. Berkley:University of California, 1984

FOUCAULT,M. História da sexualidade I. A vontade de saber. Rio de Janeiro: Graal, 1982.

FRANÇAJÚNIOR, I ; AYRES,J.R.C.M., 2000. Amamentar é um direito humano? In: Seminário Amamentar é um direito humano. WABA (World Alliance Breastfeeding action), São Paulo: Secretaria de Estado de Saúde-SP , SENAC-SP, mimeo.

FRANCHETTO,B. et al. Antropologia e feminismo. Perspectivas Antropológicas da Mulher. Rio de Janeiro: Zahar, 1982.

JORDAN, B.Birth in four cultures. Illinois:Waveland Press, 1993

GEERTZ,C. A interpretação das culturas. Rio de Janeiro: Koogan,1982. 
MALINOWSKI,B. Los argonautas del pacifico occidental. Buenos Aires: Altaya: 1972.

MAUSS, M. As técnicas corporais.In: Sociologia e Antropologia. São Paulo:EPU/EDUSP, 1974.

ODENT, Michel. A cientificação do amor. Florianópolis, Terceira Margem: 1999.

TORNQUIST, C.S. Parto e Poder: o movimento pela humanização do parto e do nascimento. Florianópolis. (Tese de Doutorado em Antropologia). UFSC, 2004.

SALEM,Tânia. Sobre o casal grávido: incursão em um universo ético. (Tese de Doutorado em Antropologia Social). Rio de Janeiro: Museu Nacional,1983. 